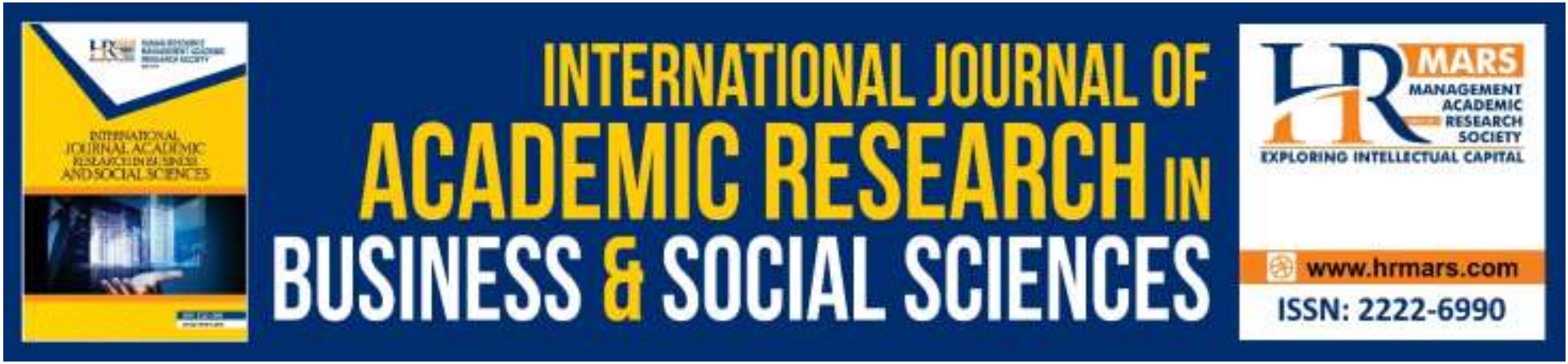

\title{
Effects of Organizational Justice and Organizational Citizenship Behavior on Employee Turnover Intention
}

Noraini Rusbadrol, Siti Aisyah Panatik, Azlineer Sarip \& Faizah Mohd Fakhruddin

To Link this Article: http://dx.doi.org/10.6007/IJARBSS/v11-i17/11393 DOI:10.6007/IJARBSS/v11-i17/11393

Received: 08 August 2021, Revised: 29 August 2021, Accepted: 20 September 2021

Published Online: 24 October 2021

In-Text Citation: (Rusbadrol et al., 2021)

To Cite this Article: Rusbadrol, N., Panatik, S. A., Sarip, A., \& Fakhruddin, F. M. (2021). Effects of Organizational Justice and Organizational Citizenship Behavior on Employee Turnover Intention. International Journal of Academic Research in Business and Social Sciences, 11(17), 80-91.

Copyright: (C) 2021 The Author(s)

Published by Human Resource Management Academic Research Society (www.hrmars.com)

This article is published under the Creative Commons Attribution (CC BY 4.0) license. Anyone may reproduce, distribute, translate and create derivative works of this article (for both commercial and non-commercial purposes), subject to full attribution to the original publication and authors. The full terms of this license may be seen at: http://creativecommons.org/licences/by/4.0/legalcode

Special Issue Title: Empowering Community and Beyond, iRandau, 2021, Pg. 80 - 91 


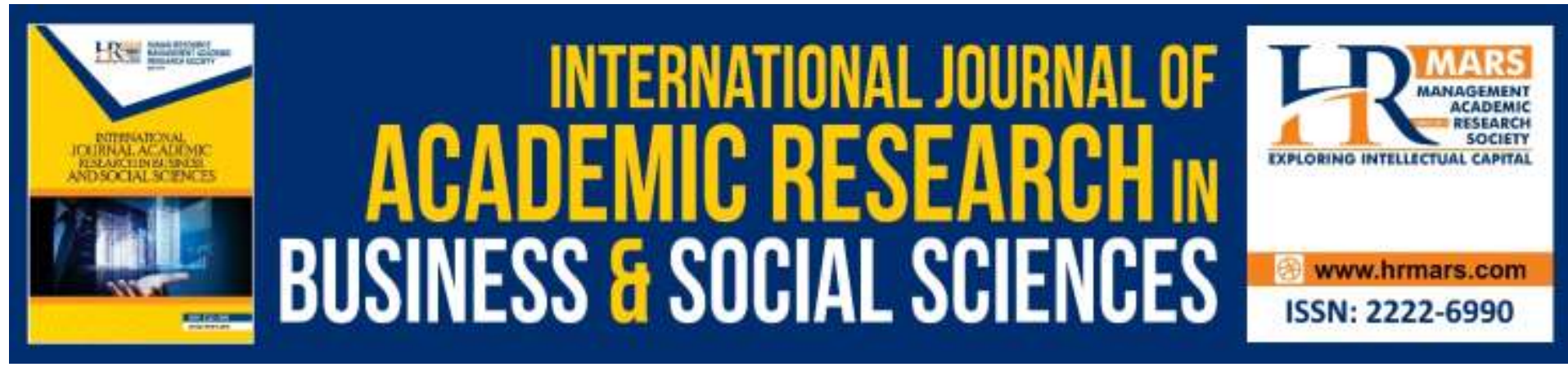

\title{
Effects of Organizational Justice and Organizational Citizenship Behavior on Employee Turnover Intention
}

\author{
Noraini Rusbadrol, Siti Aisyah Panatik, Azlineer Sarip \& Faizah \\ Mohd Fakhruddin \\ School of Human Resource Development and Psychology, Faculty of Social Sciences and \\ Humanities, Universiti Teknologi Malaysia, 81310 Johor Bahru, Johor, Malaysia. \\ Email: norainirusbadrol@utm.my
}

\begin{abstract}
Employee turnover is an on-going concern among researchers due to its negative impacts towards organizations. Given the rising rate of employee turnover in a utility company in Malaysia, some attention should be paid on the factors that might influence the employees to leave the organization. Underpinned by social exchange theory, the study was aimed to identify the relationship between organizational justice, organizational citizenship behaviour, and turnover intention. Besides, this study aims to test the mediation effects in the research framework. Research hypotheses are tested by conducting a cross-sectional survey at the utility company located in Klang Valley. Using convenience sampling method, 750 employees were involved which yielded 391 usable responses. Partial least squares structural equation modeling technique was applied to test the proposed research hypotheses. The results have confirmed that distributive justice was significantly related with the turnover intentions of the staff, whereas the other three dimensions of organizational justice were not in the hypothesized negative direction. The results also confirmed the mediatory effect of organizational citizenship behaviour directed at individuals on the relationships between procedural justice and turnover intention. This study provides useful insights for managers and HR practitioners to take remedial measures to retain the employees for long-term.
\end{abstract}

Keywords: Organizational Justice, Organizational Citizenship Behaviour, Turnover Intention

\section{Research Background}

The employee turnover phenomenon is not an entirely new thing in the labor workforce; it has been in trend for years. Employee turnover is equivalent to the loss of valuable talents, skills, knowledge, and abilities (Ballinger et al., 2011). Employee turnover is not good news for employers as its costs to an organization is high. For instance, a survey in 2016 by Deloitte, a consultancy, suggested that the combination of hiring cost and lost productivity added up to $\$ 121,000$ per departing employee (Economist, 2018). The additional cost of employee turnover includes the real recruitment cost (to replace those who leave) in terms of 
advertising, travel, and interview time, as well as cost of background checks, drug screens, and specialty tests. It means that the loss of workers will cause employers to incur sizeable personnel cost, including the increment in expenditures for the recruitment, replacement, and training of new employees (Peterson \& Luthans, 2006). It shows that the potential additional cost is high as replacing workers can be expensive. Accordingly, employers will have to pay $\$ 600$ billion in turnover cost in 2018; this figure is expected to increase to $\$ 680$ billion by 2020 (Fox, 2018).

In an attempt to identify the factors of actual turnover, most scholars have suggested that an employee's actual turnover is derived from his or her behavioural intentions (Campbell et al., 2013). Behavioural intentions represent the degree to which a person has formulated conscious plans to perform or not to perform behaviour. As postulated in theory of propositional control by Dulany (1968), the immediate antecedent of overt behaviour is the person's intention to perform the behaviour. The behavioural intentions of an individual are assessed by the subject's willingness to engage in various behaviours with respect to or in the presence of a given person or object (Fishbein, 1973). Based on this view, it can be summarized that there is a need for further empirical researchers to identify the factors that are related with employees' turnover intentions.

Researchers have suggested that turnover intentions are predicted by organizational justice (Farooq \& Farooq, 2014; Meisler, 2013). The employees' intentions to leave may decrease when they perceive fairness of the outcomes (distributive justice), organizational procedures (procedural justice), interpersonal treatment from managers (interpersonal justice), or information given by the organizational authorities (informational justice) (Al Afari \& Abu Elanain, 2014; Kiersch \& Byrne, 2015). Although the importance of organizational justice has been validated by the literature on management, it has not garnered much attention from the Malaysian utility industry. Therefore, there is still much to be learned with regards to the role of organizational justice in predicting the turnover intentions in the context of Malaysian utility industry. This effort will provide an understanding as to whether fairness at the workplace may induce positive feelings among the employees of the utility company to remain loyal and stay with the company.

Despite the influence of organizational justice in explaining turnover intentions, a past study has found that its impact on the employees' turnover intention reduced when a mediator was included in the relationship (Bakri \& Ali, 2015). This finding implies the involvement of other variables in a mechanism that links organizational justice with the employees' intentions to leave. Based on the social exchange theory (Blau, 1964), this study has noted that OCB mediated the relationship between organizational justice and turnover intentions. As such, employees who perceived justice at the workplace were motivated to display more citizenship behaviours towards the individuals (OCB-I) and the organization as a whole (OCBO) (Haque \& Aslam, 2011). OCB in turn reduced the employees' intentions to leave the current company (Islam et al., 2016). Although empirical researchers are yet to examine the role of $O C B$ as a mediator in the relationship, this prediction was consistent with the social exchange theory (Blau, 1964) and it was therefore worthwhile to be examined.

In short, the aim of this research was to determine the extent to which aspects like organizational justice and OCB contributed to the employees' turnover intentions. Specifically, this study tested a model that examined the mediatory process that underlie the relationship between organizational justice and turnover intentions of the employees of the utility company. 


\section{Purpose of the Study}

Generally, the purpose of this study was to investigate the relationships of organizational justice, organizational citizenship behaviours (OCBs), and turnover intentions among the employees of the utility company. The specific objectives of this study are:

- $\quad$ To determine the relationship between organizational justice and turnover intentions of the employees.

- To determine the mediation effect of organizational citizenship behaviours (OCB-I and OCB-O) on the relationship between organizational justice and turnover intentions relationship of the employees.

\section{Literature Review}

\section{Turnover Intentions}

Employee turnover is the measure of the extent to which existing employees leave an organization and new ones are engaged (Zotorvie, Kudo, \& Adade, 2017). It is normally calculated as the number of employees leaving an organization in a year compared to the average number of employees in a year expressed in percentage terms. Many researchers relied on employee turnover intention to represent actual turnover due to difficulties in measuring actual turnover (Park, Boyle, Bergquist-Beringer, Staggs, \& Dunton, 2014). Since the phase of employees' turnover intention leads to the actual turnover (Bryant \& Allen, 2013), hence, the utilisation of the turnover intention concept in explaining actual turnover in this study is deemed appropriate.

According to Tett and Meyer (1993, p. 262), turnover intention is defined as "the last in a sequence of withdrawal cognitions, a set to which thinking of quitting and intent to search for alternative employment also belongs". That means, turnover intention exists when an individual has a thought of leaving his or her current organization. This study uses the theory of planned behaviour (Ajzen, 1991) to explain employees' turnover intention. This theory was developed to extend the theory of reasoned action (Ajzen \& Fishbein, 1980), whereby it added the construct of perceived behavioural control to the original reasoned action theory. The extension allows researchers to predict behaviour under someone's control, instead of behaviour due to situations beyond his or her control. Importantly, theory of planned behaviour emphasized on the prediction of intentions (Ajzen, 2011), or an individual's readiness to perform a given behaviour. As suggested in this theory, perceived behavioural control tends to influence behaviour (actual turnover) either directly or through behavioural intention (turnover intention). From the perspective of the theory of planned behaviour (Ajzen, 1991), an individual's intention to perform a certain behaviour is a strong predictor of that behaviour (Chong \& Monroe, 2015). In other words, intention is assumed to capture the motivational factors that influence an actual behaviour.

Therefore, measuring turnover intention in this study can shed light in understanding the factors that influence employees' intention to leave the organization. For the purpose of this study, the variables of organizational justice and organizational citizenship behaviour (OCB) serve as the predictor of employees' turnover intention. The details of these variables are explained in their respective sections.

\section{Organizational Justice}

Organizational justice is defined as individual's perceptions of fairness at their workplace (Greenberg, 1987). In other words, organizational justice refers to the extent to which individuals believe that the outcomes (rewards) they receive and the ways they are treated 
within organizations are fair, equitable, and in line with the expected moral and ethical standards. It has been recognized that organizational justice takes several different dimensions as summarized in Figure 1.

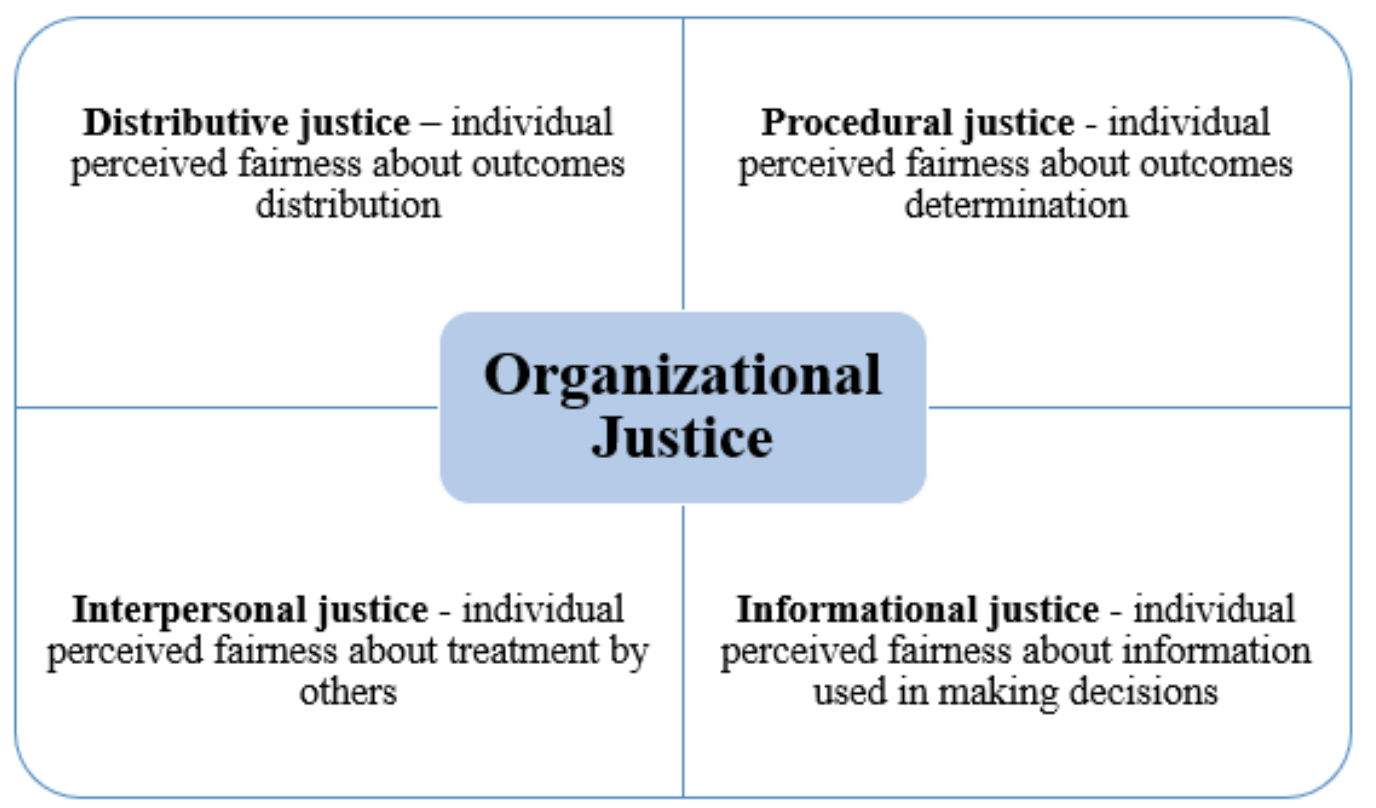

Figure 1: Four dimensions of organizational justice (Greenberg, 1993a)

\section{a) Distributive Justice}

Distributive justice is defined as employees' perception of fairness on the outcomes one receives at the workplace (Adams, 1965). Building on the work of Adams (1965), distributive justice reflects employees' concerns about the fairness of resources distributed within the organization, such as pay, promotion, recognition, and other rewards. In other words, this dimension of organizational justice emphasizes on individual's beliefs that they get rewards that they deserve. According to Adams (1965), employees perceive fairness by first assessing the perceived inputs (work contributions) to the outcomes (rewards) they received. They proceed to compare the ratio of rewards allocated between them and other employees to determine whether the rewards received for their work contributions are fair.

\section{b) Procedural Justice}

Procedural justice is defined as the employees' perceptions of the fairness on the process used to determine the distribution of rewards (Leventhal, Karuza, \& Fry, 1980). Basically, it reflects employees' concern about the fairness of the procedures used to determine the rewards given to them. In other words, employees are not only focused on how much they received (distributive justice), but also the process involved in determining the distribution of those outcomes to each employee (procedural justice) (Nowakowski \& Conlon, 2005). For instance, employees are likely to perceive fairness in the process when their job performance is evaluated by someone who is very familiar with the job that they performed.

c) Interpersonal Justice

Interpersonal justice refers to the politeness, sensitivity, and respect that individuals receive from their managers during procedures. This form of justice emphasizes on individual's belief that they deserve to be treated with respect. Individuals will perceive a high level of 
interpersonal justice when their superior exhibits a high level of dignity and respect while explaining outcomes and procedures.

d) Informational Justice

Informational justice refers to the information, justification, or thorough explanation provided by decision makers regarding the reason behind the decision. This form of justice emphasizes on the information used in explaining outcomes and procedures. Individuals will perceive a high level of informational justice when their superior provides them with accurate information and thorough explanation on certain decisions made by senior management.

Inspired by Greenberg's (1993) four-factor structure of organizational justice, empirical findings in the past clearly support those different forms of justice have different impact in understanding fairness perceptions at the workplace. In fact, examining multiple dimensions may assist researchers to discover further interactions and differences between the organizational justice dimensions (Bies, 2005). Hence, this study applies four dimensions of organizational justice (distributive, procedural, interpersonal, and informational) as a predictor that may directly or indirectly influence employees' turnover intention.

Equity theory (Adams, 1965) emphasized on employees' perceptions of how fairly they are treated at their workplace. Adams (1965) argued that employees will take action in order to eliminate or reduce the feeling of inequity. For instance, employees who believe that they are overpaid (experienced positive inequity) are likely to increase their inputs such as more work effort or productivity. By contrast, employees who believe that they are underpaid (experienced negative inequity) will likely reduce their effort or work quality. Despite adjusting their individual inputs, they might also resolve the negative inequity by demanding to raise outcomes such as negotiate for a promotion or increase in pay. Finally, some employees might take action of simply ignoring the situation that caused them the inequity feeling. For example, they increase their absence, transfer to other department, or simply quit their current job and find a new employer.

That means, employees are likely to contribute extra efforts and do not intend to leave when they perceive that their firm is being fair to all employees. As such, a high perceived organizational justice is vital in inducing motivation for employees to perform OCB as well as reducing their intention to quit or move to another organization. The following section discusses organizational citizenship behaviour (OCB) as another variable that influence employees' turnover intention.

\section{Organizational Citizenship Behaviours (OCB)}

Organ (1988) originally defined organizational citizenship behaviour (OCB) as "individual behaviour that is discretionary, not directly or explicitly recognized by the formal reward system, and that in the aggregate promotes the effective functioning of the organization. By discretionary, we mean that the behaviour is not an enforceable requirement of the role or the job description, that is, the clearly specifiable terms of the person's employment contract with the organization; the behaviour is rather a matter of personal choice, such that its omission is not generally understood as punishable" (p. 4). It means, this behaviour involves employees' actions and attitudes at the workplace that was conducted beyond the job requirement, and it significantly contributed to the organizational effectiveness (Organ, 1988). 
In 1991, Williams and Anderson classified the OCB into two main categories, organizational citizenship behaviours that benefit the individuals (OCB-I), and organizational citizenship behaviours that benefit the organization (OCB-O). In other words, Williams and Anderson (1991) looked at the OCBs as demonstrated by the employees and to whom those OCBs are directed. They characterized OCB-I as "behaviours that immediately benefit specific individuals and indirectly through this means contribute to the organization" (p.602). For instance, voluntarily assisting colleagues who have heavy workloads or facilitating others with relevant job tasks. On the other hand, OCB-O was characterized as "behaviours that benefit the organization in general" (Williams \& Anderson, 1991), such as adhere to company's informal rules, provide advance notice whenever they are unable to come to work, or assist the organization to achieve its goals.

\section{The Relationship between Organizational Justice, Organizational Citizenship Behaviours (OCB), and Turnover Intentions}

This study drawn on social exchange theory (Blau, 1964) as the underpinning theory for understanding the link between employees' turnover intention and its predictors (organizational justice and OCBs).

There is ample evidence in the literature that organizational justice is consistently negatively related to turnover intentions (Al Afari \& Elanain, 2014; Bakri \& Ali, 2015), apart from having a significant positive relationship with OCB (Elamin \& Tlaiss, 2015). Furthermore, OCB is found to be negatively related to turnover intentions (Priyadharshini \& Mahadevan, 2014).

Although the aforementioned studies have confirmed the significance of the relationship of OCB with both organizational justice and turnover intentions, there has yet to be an investigation on the mediatory role of $O C B$ in the organizational justice-turnover intention relationship. Despite the gap in literature, the mediatory effect of OCB (OCB-I and OCB-O) can be explained by referring to Adams' (1965) equity theory and Blau's (1964) social exchange theory. In the perspective of equity theory (Adams, 1965), perceived unfairness in the reward distribution (distributive justice) and reward determination (procedural justice) systems causes employees to react to the unfair situation by reducing OCB-I and OCB-O (Haque \& Aslam, 2011). This in turn triggers the employees' intentions to leave the current organization as a response to their perceptions of unfairness (Paillé et al., 2010).

The social exchange theory (Blau, 1964) arrives at a similar conclusion. From perspective of social exchange, employees are likely to reciprocate fair treatment (interpersonal and informational justice) by exhibiting high levels of OCB-I and OCB-O (Lilly, 2015) and less intention to leave (Cole et al., 2010). Based on this point of view, OCB-I and OCB-O are likely to serve as key mechanisms which link organizational justice (distributive, procedural, interpersonal, and informational justice) with an individual's withdrawal behaviour (turnover intention). Specifically, the feeling of unfairness leads to a reduction in the employees' OCB towards individuals and OCB towards the organization, which, in turn, increases the employees' intentions to leave the organization.

To summarize, social exchange theory highlighted that if employees fail to find benefits in the exchange process with the organization, they are likely to end up with actual turnover or search for other employment. As this study relies on this theory, it is understood that employees who perceive fairness in the organization tend to exhibit more OCB (Al Afari \& Elanain, 2014) and they are obliged to remain (De Gieter et al., 2012). In fact, employees have less intention to leave an organization when they exhibit OCB towards their organization as a whole (Wee, Ahmad, \& Fen, 2012). 
Based on the fact that organizations can increase the tendency of employees to exhibit citizenship behaviours and also to remain with the employer, this theory was therefore reasonable to be employed in this study. Using the theoretical underpinning of social exchange, this study examined the relationships between employees' turnover intention and its predictor (organizational justice and $\mathrm{OCBs}$ ). In addition, the researcher also investigated the mediating roles of OCB-I and OCB-O.

\section{Research Framework}

The research framework as illustrated in Figure 2 was developed based on literature reviews that have been discussed earlier. This framework provides a clear picture on the investigation of turnover intention among employees.

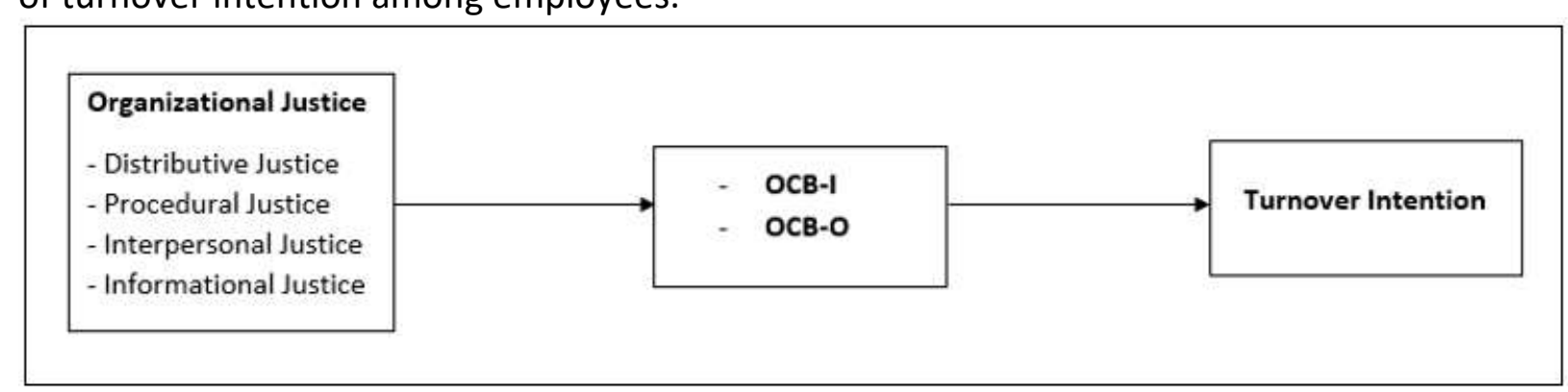

Figure 2: Research Framework

\section{Methodology}

A quantitative method was applied for this study by way of data collection through selfadministered questionnaires. The questionnaire used was in the form of close-ended questions. Thus, respondents must choose one answer from multiple choice of answer given. In regards to variable measurement, a cross-sectional study design was utilized where variables are measured at one same point in time.

In this study, the questionnaire is divided into four (4) sections which are Section A, B, C, and D. Section A consists of items regarding the background of respondents. While Section $B$ consists of items regarding organizational justice. Next, Section $C$ consists of items regarding the mediator variable which is organizational citizenship behaviours (OCBs), and finally, Section $D$ consists of items regarding the dependent variable which is respondents' turnover intention.

Overall, there are 55 items in a set of questionnaires for this study. The distribution of the questionnaire is listed in the Table 1.

Table 1: Distribution of the questionnaire

\begin{tabular}{lll}
\hline Section & Variables & $\begin{array}{l}\text { Number } \\
\text { of Items }\end{array}$ \\
\hline A & Respondents' Demography & 8 \\
B & Organizational Justice & 20 \\
C & Organizational Citizenship Behaviours (OCBs) & 24 \\
D & Turnover Intention & 3 \\
\hline TOTAL & & $\mathbf{5 5}$ \\
\hline
\end{tabular}


In this study, respondents were drawn from population of 750 employees at the utility company in the Klang Valley area. The samples consist of employees who are involved in the day-to-day operations, and thus play an important role in the success of the company. The employees involved are from two categories of employment (executives and non-executives) which include managers, executives, engineers, technicians, secretaries, clerks, and receptionists.

The IBM SPSS version 24 and SmartPLS 3.2.8 (Ringle, Wende, \& Becker, 2015) were used as the processing tools in data analysis. Descriptive analysis was utilized to describe the characteristics of respondents in this study. It is useful in analyzing respondents' demography by providing information about percentage, range of scores or a simple summary about the research respondents. Besides, the structural equation modelling was run to test the relationships and the mediation effects of variables in this study.

\section{Findings and Discussions}

Among the four dimensions of organizational justice (distributive, procedural, interpersonal, and informational), the results have confirmed that distributive justice was significantly and negatively related with the turnover intentions of the utility company's staff. However, the relationships between turnover intentions and the other three dimensions of organizational justice (procedural, interpersonal, and informational) were not in the hypothesized negative direction.

This finding is consistent with previous research by Bakri and Ali (2015) who have found an association between perceived fairness of the remunerations and turnover intentions of employees in the service sector. Their findings have implied that distributive justice was a significant predictor of the employees' intentions not to leave their employers. It has been revealed that employees who tended to show positive feelings towards distributive justice were likely to have less intentions to quit. In general, the more the employees perceive distributive justice at the workplace, the more likely they will continue to work and stay with their current organizations. In other words, with high levels of distributive justice, employees will perceive that the company is fair in the allocation of rewards, which then decreases their intentions to quit. Consistent with previous researchers, this study has found distributive justice was an important predictor to reduce the turnover intentions of the staff of the utility company.

Next, further analysis on the mediation effects showed that OCB-I mediated the relationships between procedural justice with turnover intention. This finding explains that employees are more willing to exhibit citizenship behaviours when they perceive fairness in the organizational procedures (Al Afari \& Elanain, 2014). Those who tend to show positive feelings towards procedural justice are likely to adopt helpful behaviours to benefit specific individuals at the workplace, which in turn increases individual and group performance. Even though the perception of organizational justice motivates employees to display citizenship behaviours, the tendency of employees to perform the same can be reduced when the employees are bounded by high levels of formalization and inflexibility at their workplace.

\section{Conclusion}

The relationships between organizational justice, organizational citizenship behaviours (OCBs), and turnover intentions of the employees of a utility company have been examined in this study. To fill the gaps in the literature, this study has drawn attention to the roles of 
OCB towards individuals (OCB-I) and OCB towards the organization (OCB-O) as mediators of the relationships.

By using the PLS-SEM method in SmartPLS software, the results of this study have demonstrated that OCB-I mediated the effects of organizational justice on the turnover intentions of the employees. Based on the results of this study, it is suggested that the management of the utility company to take into consideration the importance of the employees' willingness to exhibit citizenship behaviours in influencing their intentions to leave the company. Moreover, further researchers can combine qualitative and quantitative approaches to further understand the factors that can influence an employee's intention to leave his or her current organization.

\section{References}

Adams, J. S. (1965). Inequity in social exchange. Advances in Experimental Social Psychology, 2(267-299).

Ajzen, I. (1991). The theory of planned behavior. Organizational Behavior and Human Decision Processes, 50(2), 179-211.

Ajzen, I. (2011). The theory of planned behaviour: Reactions and reflections. Psychology \& Health, 26(9), 1113-1127.

Ajzen, I., \& Fishbein, M. (1980). Understanding attitudes and predicting social behaviour. Prentice-Hall

Al Afari, T. S., \& Abu Elanain, H. M. (2014). Procedural and distributive justice as mediators of the relationship between interactional justice and work outcomes: An empirical study of the UAE public health care sector. Journal of Applied Business Research, 30(4), 1091-1108.

Bakri, N., \& Ali, N. (2015). The impact of organizational justice on turnover intention of Bankers of KPK, Pakistan: The mediator role of organizational commitment. Asian Social Science, 11(21), 143-147.

Ballinger, G., Craig, E., Cross, R., \& Gray, P. (2011). A stitch in time saves nine: Leveraging networks to reduce the costs of turnover. California Management Review, 53(4), 111 133.

Bies, R. J. (2005). Are Procedural Justice and Interactional Justice Conceptually Distinct? In J. Greenberg \& J. A. Colquitt (Eds.), Handbook of organizational justice (pp. 85-112). Lawrence Erlbaum Associates Publishers.

Blau, P. (1964). Exchange and Power in Social Life. New York: Wiley.

Bryant, P. C., \& Allen, D. G. (2013). Compensation, Benefits and Employee Turnover: HR Strategies for Retaining Top Talent. Compensation \& Benefits Review, 45(3), 171-175.

Campbell, N. S., Perry, S. J., Maertz, C. P., Allen, D. G., \& Griffeth, R. W. (2013). All you need is. resources: The effects of justice and support on burnout and turnover. Human Relations, 66(6), 759-782.

Chong, V. K., \& Monroe, G. S. (2015). The impact of the antecedents and consequences of job burnout on junior accountants' turnover intentions: A structural equation modelling approach. Accounting \& Finance, 55(1), 105-132.

Cole, M. S., Bernerth, J. B., Walter, F., \& Holt, D. T. (2010). Organizational justice and individuals' withdrawal: Unlocking the influence of emotional exhaustion. Journal of Management Studies, 47(3), 367-390.

De Gieter, S., De Cooman, R., Hofmans, J., Pepermans, R., \& Jegers, M. (2012). Pay-level satisfaction and psychological reward satisfaction as mediators of the organizational 
justice-turnover intention relationship. International Studies of Management \& Organization, 42(1), 50-67.

Dulany, D. E. (1968). Awareness, rules, and propositional control: A confrontation with SR behavior theory. In T. Dixon \& Deryck Horton (Eds.), Verbal Behavior and General Behavior Theory. (pp. 340-387) Prentice-Hall.

Economist, T. (2018). The high costs of staff turnover. Retrieved from https://www.economist.com/business/2018/09/22/the-high-costs-of-staff-turnover

Elamin, A. M., \& Tlaiss, H. A. (2015). Exploring the relationship between organizational citizenship behavior and organizational justice in the Islamic Saudi Arabian context. Employee Relations, 37(1), 2-29.

Fishbein, M. (1973). The prediction of behaviors from attitudinal variables. Advances in Communication Research, 3-31.

Fox, C. (2018). Work Institute Releases National Employee Retention Report. Retrieved from https://workinstitute.com/about-us/newsevents/articleid/2259/2018\%20retention\%20report

Greenberg, J. (1987). A taxonomy of organizational justice theories. Academy of Management Review, 12(1), 9-22.

Greenberg, J. (1993). The social side of fairness: Interpersonal and informational classes of organizational justice. In R. Cropanzano (Ed.), Justice in the workplace: Approaching fairness in human resource management, Lawrence Erlbaum Associates, Hillsdale, NJ.

Haque, A., \& Aslam, M. S. (2011). The influence of distributive justice on organizational citizenship behaviors: Mediating role of emotional exhaustion and organizational attachment. International Journal of Business and Social Science, 2(15).

Leventhal, G. S., Karuza, J., \& Fry, W. R. (1980). Beyond fairness: A theory of allocation preferences. Justice and Social Interaction, 3, 167-218.

Lilly, J. (2015). The Impact of Justice Type on Organizational Citizenship Behavior: Do Outcome Favorability and Leader Behavior Matter? Current Psychology, 34(1), 26-49.

Nowakowski, J. M., \& Conlon, D. E. (2005). Organizational justice: Looking back, looking forward. International Journal of Conflict Management, 16(1), 4-29.

Organ, D. W. (1988). Organizational citizenship behavior: The good soldier syndrome. Lexington, M. A.: Lexington Books.

Paillé, P., \& Grima, F. (2011). Citizenship and withdrawal in the workplace: Relationship between organizational citizenship behavior, intention to leave current job and intention to leave the organization. The Journal of Social Psychology, 151(4), 478-493.

Park, S. H., Boyle, D. K., Bergquist-Beringer, S., Staggs, V. S., \& Dunton, N. E. (2014). Concurrent and lagged effects of registered nurse turnover and staffing on unitacquired pressure ulcers. Health Services Research, 49(4), 1205-1225.

Peterson, S. J., \& Luthans, F. (2006). The impact of financial and nonfinancial incentives on business-unit outcomes over time. Journal of Applied Psychology, 91, 156-165.

Priyadharshini, S. L., \& Mahadevan, A. (2014). Mediating role of organizational citizenship behavior on HRM practices and turnover intention among production engineers. International Journal of Organizational Behaviour \& Management Perspectives, 3(2), 994-1003.

Ringle, C. M., Wende, S., \& Becker, J.-M. (2015). SmartPLS 3. Boenningstedt: SmartPLS GmbH, http://www.smartpls.com. 
Tett, R. P., \& Meyer, J. P. (1993). Job satisfaction, organizational commitment, turnover intention, and turnover: A path analysis based on meta-analytic findings. Personnel Psychology, 46, 259-293.

Wee, Y. G., Ahmad, K. Z., \& Fen, Y. S. (2012). Promoting organizational citizenship behaviour through high involvement human resource practices: An attempt to reduce turnover intention. Journal of Law and Social Sciences, 1(1), 163-168.

Williams, L. J., \& Anderson, S. E. (1991). Job satisfaction and organizational commitment as predictors of organizational citizenship behaviors. Journal of Management, 17, 601617.

Zotorvie, J. S. T., Kudo, M. B., \& Adade, T. C. (2017). A Survey of Factors that Influence the Level of Job Satisfaction and Turnover Intention of Professional Accountants in Ghana. International Journal of Academic Research in Business and Social Sciences, 7(10), 4156. 